\title{
Enhanced training in emergency medicine: the search and application process
}

\author{
Brent Thoma, MD, $\mathrm{MA}^{*}{ }^{\dagger}$; Rohit Mohindra, MD, MASc ${ }^{\ddagger}$; Robert A. Woods, MD, MMEd ${ }^{\dagger}$
}

Enhanced competency training is becoming an increasingly prominent aspect of the Royal College of Physicians and Surgeons of Canada (RCPSC) emergency medicine (EM) program. Defined loosely as additional training in an area relevant to the practice of $\mathrm{EM}$, the enhanced competency training pursued by Canadian EM residents can include accredited subspecialty fellowships such as intensive care or pediatric EM; unaccredited fellowships in areas such as simulation or emergency medical services; and graduate degree programs in medical education, public health, epidemiology, or business administration. These programs are pursued by a large number of EM trainees in the RCPSC program, often during their fourth postgraduate year of training.

Despite their prominence, little has been published on applying to enhanced training programs in the Canadian context. The lack of literature, the authors' experiences applying for additional training, and the importance of this topic for EM residents were the impetus for this article. Herein, we outline the current status of enhanced training and provide advice to interested EM residents.

\section{THE CURRENT STATUS OF ENHANCED} TRAINING PROGRAMS

In 2008, the RCPSC formally modified the EM training requirements to include "a minimum of six (6) months devoted to achieving particular expertise either in a scholarly activity or a clinical area, pertinent to the practice of the specialty of Emergency Medicine."1 When combined with the 4 or more additional months that EM trainees are able to devote to electives, ${ }^{1}$ it is possible for many to devote a full year of their residency to such a pursuit.

The ability to pursue an advanced degree, fellowship, or subspecialty program while still considered a resident trainee is unique to EM in Canada. However, not all residents will use an entire year. Residents in academic difficulty are unlikely to be permitted to leave their programs for extended periods, residents may not want to study only one area for an entire year, and the flexibility to pursue enhanced training varies between programs, institutions, and provinces. In 2011, EM residents called for increased opportunities for enhanced training within Canada and the development of a comprehensive fellowship registry. ${ }^{2}$

\section{THE DECISION TO PURSUE ENHANCED TRAINING}

The decision to pursue enhanced training is complex. The Canadian EM job market is heterogeneous and fluid in nature. Depending on preferred location, desire for academic/clinical mix, and niche interest, it may or may not be the best choice. Many competent residents instead wish to enhance their clinical skills and address areas of perceived deficits. Not undertaking enhanced training during residency generally does not preclude trainees from pursuing it later. The breadth of experiences of current EM physicians speaks to the fact that there are multiple ways to reach career goals.

The decision to pursue enhanced training should be an individual one. It is important to involve family and partners in this decision, because it may require geographical change, additional time as a trainee, and substantial cost. All RCPSC residency programs must provide ongoing career counselling, ${ }^{3}$ and this should

From the *Learning Laboratory and Division of Medical Simulation, Department of Emergency Medicine, Massachusetts General Hospital, Boston, MA; †Emergency Medicine, University of Saskatchewan, Saskatoon, SK; and \#Emergency Medicine Residency Training Program, McGill University, Montreal, QC.

Correspondence to: Dr. Brent Thoma, EM Residency Training Program, Room 2688, Royal University Hospital, 103 Hospital Drive, Saskatoon, SK S7N 0W8; Email: brent.thoma@usask.ca 
be used. Speaking to mentors, program directors, EM clinicians, and senior residents with a variety of niche interests will help determine what, if any, enhanced training is required for a desired career path. Additionally, the Emergency Medicine Residency Association coordinates mentorship programs for EM residents interested in academics, ${ }^{4}$ ultrasound, ${ }^{5}$ global health, ${ }^{6}$ international research, ${ }^{7}$ wilderness medicine, ${ }^{8}$ and pediatric EM. ${ }^{9}$

\section{FINDING ENHANCED TRAINING PROGRAMS}

A huge variety of advanced diplomas and degrees are available at institutions within Canada and abroad. During their enhanced training time, residents can pursue extended training in a specific clinical area, complete 1 year fellowships or the first year of a 2-year fellowship (Table 1), or begin/complete an advanced

\begin{tabular}{|c|c|c|}
\hline \multirow[b]{2}{*}{ Fellowship type } & \multicolumn{2}{|c|}{ Number of fellowships } \\
\hline & United States & Canada \\
\hline Administration & 14 & 0 \\
\hline Cardiovascular emergencies & 3 & 0 \\
\hline Clinical forensic medicine & 2 & 0 \\
\hline Clinical pharmacology & 2 & 0 \\
\hline Clinical research & 9 & 0 \\
\hline Critical care and EM & 14 & 0 \\
\hline Disaster medicine & 15 & 0 \\
\hline Education & 13 & 1 \\
\hline Emergency medical services & 64 & 3 \\
\hline Environmental health & 2 & 0 \\
\hline Faculty development & 4 & 0 \\
\hline Geriatric EM & 4 & 0 \\
\hline Global international EM & 46 & 0 \\
\hline Hyperbaric medicine & 6 & 0 \\
\hline Injury control & 2 & 0 \\
\hline Legal medicine & 1 & 0 \\
\hline Medical informatics & 4 & 0 \\
\hline Neurologic/neurovascular & 4 & 0 \\
\hline Other/health policy & 10 & 0 \\
\hline Pediatric EM & 51 & 7 \\
\hline Research & 46 & 1 \\
\hline Simulation & 21 & 1 \\
\hline Sports medicine & 12 & 0 \\
\hline Toxicology & 33 & 1 \\
\hline Transport medicine & 3 & 0 \\
\hline Trauma/critical care & 7 & 2 \\
\hline Ultrasound & 62 & 2 \\
\hline Wilderness medicine & 10 & 0 \\
\hline Total & 464 & 18 \\
\hline
\end{tabular}

diploma or degree program. It may also be possible to pursue a RCPSC diploma to recognize an area of focused competence (diplomas include Sports and Exercise Medicine and Clinician Educator). ${ }^{10}$

\section{APPLYING TO ENHANCED TRAINING PROGRAMS}

There has been a significant change in the number of and the requirements for programs and the attendings who are mentoring residents facing a different job market/training environment. Figure 1 outlines one suggested timeline for applying to enhanced training programs in PGY4. This is the most common time for residents to complete enhanced training; however, enhanced training could occur earlier or over multiple years of residency.

Explore your options-The Canadian Association of Emergency Physicians (CAEP) ${ }^{11}$ and the Society for Academic Emergency Medicine (SAEM) ${ }^{12}$ fellowship databases provide a good outline of what is available, and reading about the programs may help narrow your interests. The programs also provide valuable information on their requirements for applicants.

Meet the programs-Although advanced diploma and degree programs generally have standardized application and admission processes, the system for fellowships is as diverse as the fellowships themselves. This makes

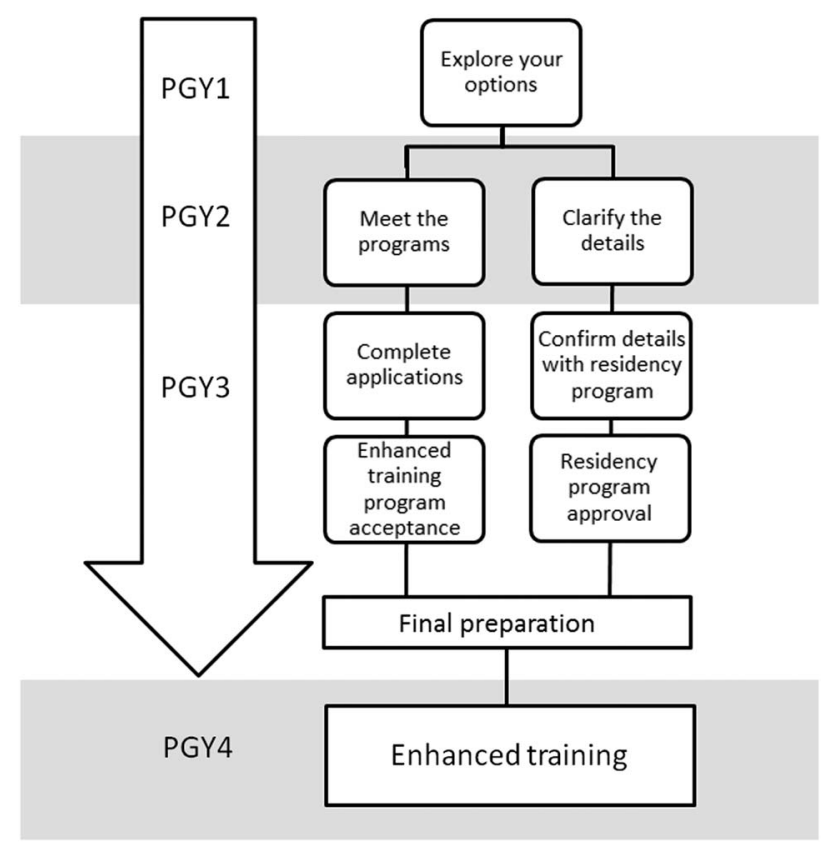

Figure 1. Suggested planning timeline for applying to enhanced training programs. 
contacting programs of interest, scheduling electives or site visits, and/or meeting them at a conference a worthwhile undertaking.

Clarify the details-The specific details of the application process are important for both fellowships and advanced degrees, but they are especially important if you are considering training outside of your home institution. Some things to clarify include the following:

- Whether the program would consider a fourth-year resident (Many fellowships are designed to be completed after residency training.)

- Whether it is possible and/or required to work clinically as a resident or to moonlight

- Whether there are any exams (e.g., United States Medical Licensing Examination [USMLE]) or licensing requirements for clinical work

- Whether there are costs associated with the program and whether financial support is available

- Whether it is a 1- or 2-year program and whether it can be interrupted

- Whether a visa is required and whether assistance is available to acquire it

- Whether additional malpractice insurance is required and how it can be obtained

Keep your program informed-Leaving a home institution for a large part of residency will require the support of your program and approval of your institution. Your mentors will need to provide valuable reference letters as part of your application. Having an ongoing dialogue with your program prior to investing time exploring training opportunities will ensure that your efforts are not wasted on programs that you will not be able to attend. Your program may also be able to help you find financial support.

\section{FUTURE DIRECTIONS FOR ENHANCED TRAINING}

A variety of initiatives could impact the current enhanced training environment in Canadian RCPSC-EM residency programs, including the development of competencybased medical education, the implementation of the CanMEDS 2015 framework, changes to the RCPSC-EM examination, and/or the approval of additional diploma programs. The potential impact on individual training programs underscores the importance of ongoing discussions between residents and their home programs.
Although research has been done in other fields of medicine with subspecialty training programs, ${ }^{13,14}$ little is known about EM residents' interest in and motivation for enhanced training. Research could provide better direction for career planning, inform health human resource planning, and direct resource allocation for Canadian fellowship programs.

\section{CONCLUSION}

The number and variety of enhanced training opportunities for RCPSC-EM residents are growing. CAEP and SAEM have created online repositories of accredited and unaccredited fellowship programs, and a wide variety of relevant advanced degrees are available. Canadian EM residents are encouraged to explore the myriad of options available while working with their mentors and career planning programs to find the best possible training for their life and career goals.

\section{Competing interests: None declared.}

Keywords: Fellowship, enhanced training, emergency medicine, residency

\section{REFERENCES}

1. Royal College of Physicians and Surgeons of Canada. Specialty training requirements in emergency medicine. 2008;613:1-2. Available at: http://www.emergencymedicine. utoronto.ca/Assets/EmergeMed+Digital+Assets/education/ Specialty+Training+Requirements+in+Emergency+Medicine. pdf (accessed April 2, 2014).

2. Theoret J, Sanz G, Cheng A, et al. The evolution of emergency medicine: the pressing need for "made in Canada" subspecialty training. Can 7 Emerg Med 2011; 13(6):416-20. doi:10.2310/8000.2011.110357.

3. Royal College of Physicians and Surgeons of Canada. General standards applicable to all residency programs: B standards. 2011; revised, 2013. Available at: http://www.royalcollege. $\mathrm{ca} /$ portal/page/portal/rc/common/documents/accreditation/ accreditation_blue_book_b_standards_e.pdf (accessed April 2, 2014).

4. Emergency Medicine Residency Association. EMRA Education Committee. EMRA.org. 2014. Available at: http:// www.emra.org/committees-divisions/education-committee/ (accessed April 6, 2014).

5. Ultrasound Division. EMRA.org. 2014. Available at: http:// www.emra.org/committees-divisions/ultrasound-division/ (accessed May 28, 2014).

6. International EM Fellowship Mentorship. EMRA.org. 2014. Available at: http://www.emra.org/committees-divisions/ international/international-em-fellowship-mentorship/?terms= mentorship (accessed May 28, 2014). 
7. International EM Research Mentorship. EMRA.org. 2014. Available at: http://www.emra.org/committees-divisions/ international/international-em-research-mentorship/?terms= mentorship (accessed May 28, 2014).

8. Wilderness Medicine Division. EMRA.org. 2014. Available at: http://www.emra.org/committees-divisions/wildernessdivision/ (accessed May 28, 2014).

9. Pediatric EM Division. EMRA.org. 2014. Available at: http:// www.emra.org/committees-divisions/pediatric-em-division/ (accessed May 28, 2014).

10. Royal College of Physicians and Surgeons. Area of Focused Competence (Diploma) Program. 2014. Available at: http://www.royalcollege.ca/portal/page/portal/rc/credentials/ discipline_recognition/afc_program (accessed May 28, 2014).
11. Canadian Association of Emergency Physicians. Fellowships. CAEP website. 2014. Available at: http://caep.ca/residents/ fellowships (accessed April 2, 2014).

12. Society for Academic Emergency Medicine. Fellowship directory. SAEM website. 2014. Available at: http://www.saem. org/membership/services/fellowship-directory (accessed April 2, 2014).

13. Harris MC, Marx J, Gallagher PR, et al. General vs subspecialty pediatrics. Arch Pediatr Adolesc Med 2005;159: 212-6.

14. Horn L, Tzanetos K, Thorpe K, et al. Factors associated with the subspecialty choices of internal medicine residents in Canada. BMC Med Educ 2008;8(37):epub, 1-8. doi:10.1186/1472-6920-8-37. 